\title{
Remoção da adstringência de caquis ‘Giombo’ com subdosagens de etanol
}

\author{
Astringency removal of 'Giombo' persimmon with ethanol sub-doses \\ Fernando Kazuhiro Edagi ${ }^{\mathrm{I}}$ Diego Garcia Chiou ${ }^{\mathrm{I}}$ Felipe de Angelis Monteiro Terra ${ }^{\mathrm{I}}$ \\ Ivan Sestari ${ }^{*}$ Ricardo Alfredo Kluge ${ }^{\mathrm{I}}$
}

\section{RESUMO}

O objetivo do trabalho foi avaliar a eficácia da aplicação de subdosagens de etanol na remoção da adstringência de caqui 'Giombo'. Além disso, foi avaliada a influência da temperatura e do tempo de exposição ao etanol no processo de destanização dos frutos. Assim, foram testadas diferentes doses de etanol (1,75; 3,5 e $7 \mathrm{~mL} \mathrm{~kg}^{-1}$ ou 0,3 e 0,6mL $L^{-1}$ de câmara $\left.{ }^{-1}\right)$, tempos de exposição $(6,12,24$ e 36h) e temperaturas de aplicação dos tratamentos $e$ de armazenamento após a aplicação $\left(5,20\right.$ e $\left.24^{\circ} \mathrm{C}\right)$. A exposição dos frutos à concentração de $1,75 \mathrm{~mL}$ de etanol, durante 12 horas, foi suficiente para destanizar completamente os frutos. Após a aplicação dos tratamentos, os frutos levaram quatro dias para estarem aptos ao consumo. A refrigeração de caquis 'Giombo', após o tratamento com etanol, não influenciou o posterior processo de polimerização dos taninos solúveis.

Palavras-chave: Diospyros kaki, tanino solúvel, álcool etílico, refrigeração.

\section{ABSTRACT}

The objective of this research was to evaluate ethanol sub-doses efficacy on the astringency removal of 'Giombo'. Additionally, it was evaluated the influence of temperature and ethanol exposure time on fruit deastringency. Thus, experiments were carried out with different exposition times (6, 12, 24 and 36h) and ethyl alcohol concentrations (1.75; 3.5 e $7 \mathrm{~mL} \mathrm{~kg}^{-1}$ or 0.3 and $0.6 \mathrm{~mL} \mathrm{~L} \mathrm{~L}^{-1}$ of chamber). Fruit exposition to ethanol concentration of $1.75 \mathrm{~mL}$ during $12 \mathrm{~h}$ was sufficient to remove completely the persimmon fruit astringency. After the treatment application, the fruits needed 4 days to become suitable to consumption. The process of tannin polymerization is not influenced by cold storage.

Key words: Diospyros kaki, soluble tannin, ethyl alcohol, cold storage.

\section{INTRODUÇÃO}

O caqui 'Giombo' pertence ao grupo variável, o qual apresenta adstringência e polpa clara, quando ocorre desenvolvimento partenocárpico do fruto e polpa escura, e não adstringente na presença de sementes (CAMP-DALL'ORTO et al., 1996). As cultivares adstringentes de caqui possuem elevados teores de taninos solúveis. Esses frutos, quando consumidos, ainda que levemente adstringentes, proporcionam uma sensação de secura no palato, devido aos taninos precipitarem as proteínas presentes na saliva, principalmente a amilase. Dessa forma, tornase necessária a aplicação de tratamentos pós-colheita para a remoção da adstringência antes da comercialização dos frutos.

Os métodos mais utilizados para a remoção da adstringência de caquis incluem a utilização de atmosfera com alta concentração de dióxido de carbono ou baixa concentração de oxigênio e exposição à atmosfera com vapores de etanol (ANTONIOLLI et al., 2001; ARNAL \& DEL RIO, 2003; SALVADOR et al., 2005). A efetividade desses métodos se deve ao fato de que esses tratamentos promovem a respiração anaeróbica nos frutos, e consequentemente há acúmulo de acetaldeído nos tecidos. Esse composto reage com o tanino solúvel (responsável pela adstringência), tornando-o insolúvel ou polimerizado (MATSUO \& ITO, 1982; OSHIDA et al., 1996; TAIRA et al., 1997; SALVADOR et al., 2007).

'Departamento de Ciências Biológicas, Universidade de São Paulo (USP), Escola Superior de Agricultura "Luiz de Queiroz" (ESALQ), CP 9, 13418 900, Piracicaba, SP, Brasil. E-mail: isestari@esalq.usp.br. *Autor para correspondência. 
A região de Mogi das Cruzes, (SP), é responsável por $60 \%$ da produção nacional de caqui, e o ‘Giombo' é uma das principais cultivares plantadas na região. Praticamente todos os produtores de caqui dessa região possuem pequenas propriedades, caracterizadas pelo sistema de agricultura familiar. Em decorrência da falta de capital para implementação de um sistema de câmaras para aplicação de dióxido de carbono, a solução mais econômica e eficiente para a destanização de caquis tem sido a aplicação de vapores de etanol. Entretanto, um dos problemas decorrentes da destanização de caquis com etanol é a rápida perda de firmeza da polpa, o que pode inviabilizar a comercialização do fruto precocemente.

Na prática, para realizar o processo de destanização, são utilizados longos períodos de exposição a concentrações elevadas de etanol, normalmente determinadas de forma empírica, pelos produtores, em razão do volume livre da câmara de aplicação. Dessa forma, o objetivo do trabalho foi avaliar a eficácia da aplicação de subdosagens de etanol na remoção da adstringência de caqui 'Giombo', em diferentes temperaturas e tempos de exposição dos frutos ao etanol.

\section{MATERIAL E MÉTODOS}

Os frutos do caquizeiro 'Giombo' foram colhidos em pomar comercial localizado em Mogi das Cruzes, SP (2331's 461'O e 742m de altitude), nas safras de 2006 e 2007. Em seguida, foram transportados para o Laboratório de Fisiologia e Bioquímica Póscolheita do Departamento de Ciências Biológicas da Escola Superior de Agricultura “Luiz de Queiroz”, em Piracicaba, SP, onde passaram por uma rigorosa seleção, obtendo um lote uniforme quanto ao tamanho e à coloração da casca.

No experimento preliminar 1 , os tratamentos originaram-se de diferentes concentrações de etanol (3,5 e $7 \mathrm{~mL} \mathrm{~kg}^{-1}$ de fruto) e tempos de exposição (6 e $12 \mathrm{~h}$ ), aplicados a $20^{\circ} \mathrm{C}$, com $95 \%$ UR. Após a aplicação dos tratamentos, os frutos foram armazenados nas mesmas condições de temperatura e UR praticadas durante a destanização, durante um, dois, quatro, seis, oito, 10,12 e 15 dias.

Já no experimento preliminar 2, utilizou-se uma concentração de etanol (3,5 $\mathrm{mL} \mathrm{kg}^{-1}$ de fruto), dois tempos de exposição (24 e 36h) e duas temperaturas de destanização (20 e $24^{\circ} \mathrm{C}$ ), que em combinação formaram os quatro tratamentos aplicados. Após a aplicação dos tratamentos destanizadores, os frutos foram armazenados a $20^{\circ} \mathrm{C}$ e $95 \%$ UR durante um, dois, quatro, seis, oito, 10, 12 e 15 dias.
Com base nos resultados obtidos nos experimentos preliminares, optou-se por aplicar doses menores de etanol. Assim, testaram-se duas doses de etanol (1,75 e 3,5mL kg-1 de fruto) e dois tempos de exposição (12 e 24h), além do controle (frutos não tratados com etanol), compondo cinco tratamentos nesse novo experimento. A destanização foi realizada a $22^{\circ} \mathrm{C}$, com 95\% de UR. Após a aplicação dos tratamentos, os frutos foram divididos em dois grupos. O primeiro grupo foi armazenado a $1^{\circ} \mathrm{C}$, com $95 \%$ UR, durante 20 dias, enquanto o segundo foi mantido a $22^{\circ} \mathrm{C}$, com $95 \%$ UR, durante seis dias. As análises foram realizadas na colheita, após o processo de destanização e após a retirada dos frutos do armazenamento a $1^{\circ} \mathrm{C}$ ou $22^{\circ} \mathrm{C}$.

$\mathrm{O}$ delineamento experimental utilizado em ambos os experimentos foi o inteiramente casualizado, com quatro repetições de três frutos cada. As seguintes variáveis foram analisadas: firmeza de polpa: utilizando um penetrômetro digital, com ponteira de $8 \mathrm{~mm}$ de diâmetro, com uma taxa de penetração de $2 \mathrm{~mm} \mathrm{~s}^{-1} \mathrm{em}$ dois pontos opostos da região equatorial do fruto sem casca; índice de adstringência: determinado visualmente conforme descrito por CAMPDALL'ORTO et al. (1996). Os frutos foram seccionados transversalmente, e a seguir a região da polpa exposta foi pressionada sobre uma folha de papel de filtro previamente tratada com cloreto férrico. De acordo com a escala de coloração (Figura 1), foram atribuídas as seguintes notas: 1 , não adstringente; 2 , ligeiramente adstringente; 3 , mediamente adstringente; 4 , adstringente; 5 , muito adstringente; cor de casca e de polpa: foi determinada em dois pontos equidistantes dos frutos utilizando-se um colorímetro Minolta (CR300), utilizando o sistema $L a^{*} b^{*}$, em que $L$ representa a luminosidade que varia de -100 (escuro) a +100 (claro). Os índices a* e b* são coordenadas que variam de -a* (verde) $\mathrm{a}+\mathrm{a}^{*}$ (vermelho) e de $-\mathrm{b}^{*}$ (azul) $\mathrm{a}+\mathrm{b}^{*}$ (amarelo), ambos com variação entre $-60 \mathrm{a}+60$. O índice de cor foi calculado por meio da fórmula IC $=\left(1.000 \mathrm{x} \mathrm{a}^{*}\right) /\left(\mathrm{L} \mathrm{x} \mathrm{b}^{*}\right)$, conforme descrito por MAZZUZ (1996). Valores próximos de -20 representam a coloração verde. Por outro lado, valores próximos de +20 representam a cor vermelha. A perda de massa dos frutos foi calculada pela diferença entre a massa inicial e final, sendo expressa como porcentagem da massa inicial.

Os dados obtidos, em cada experimento, foram submetidos à análise de variância (teste F), e as médias dos tratamentos foram comparadas pelo teste de Tukey, a 5\% de probabilidade de erro.

\section{RESULTADOS E DISCUSSÃO}

Com base nos resultados preliminares obtidos, observou-se que a concentração de etanol de $7 \mathrm{~mL} \mathrm{~kg}^{-1}$ de fruto não foi apropriada para a destanização 


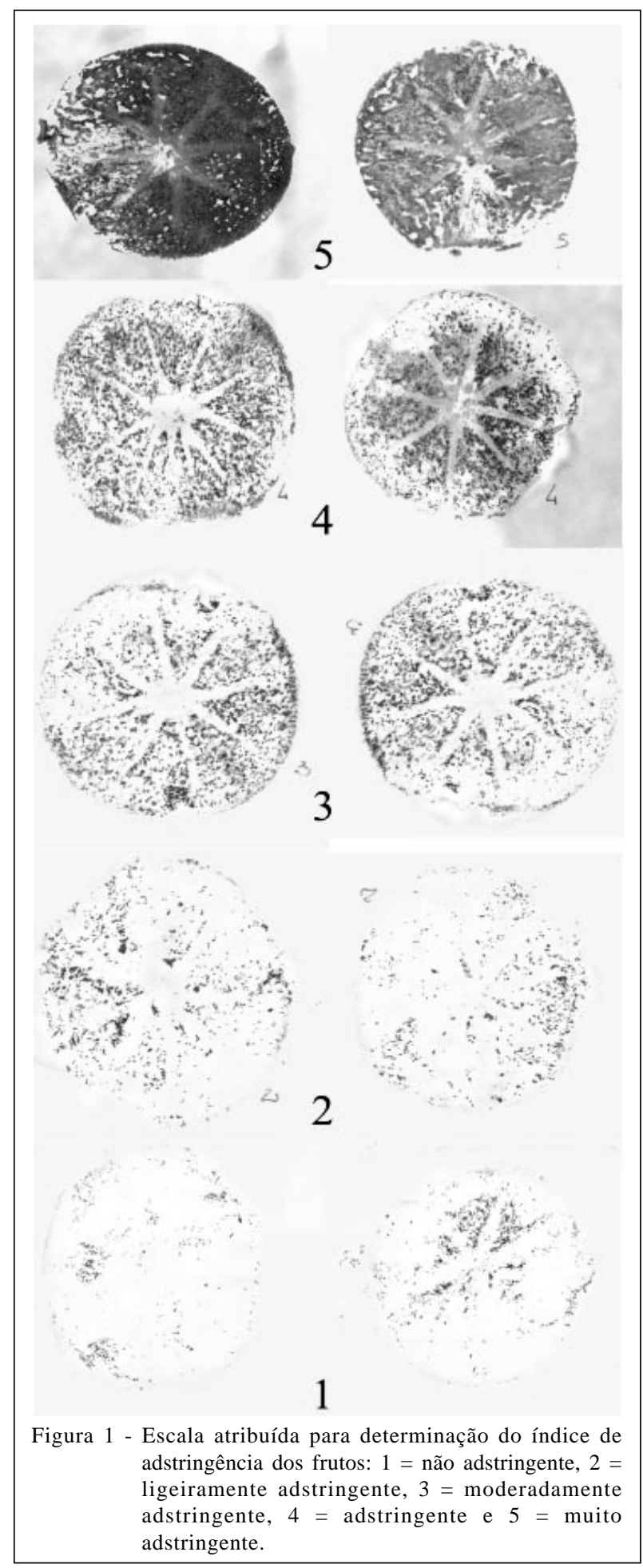

dos frutos de caqui 'Giombo', principalmente por ocasionar queimadura na casca. Considerando os valores observados de firmeza de polpa e índice de adstringência, essa concentração não apresentou diferenças significativas em relação à concentração de
$3,5 \mathrm{~mL} \mathrm{~kg}^{-1}$ de fruto (Figura 2A e 2C), que, por sua vez, não provocou queimaduras na casca dos frutos. Com o intuito de diminuir o período de seis dias entre a aplicação do vapor de etanol e a completa destanização dos frutos, optou-se por estender o período de exposição dos frutos ao etanol. Assim, verificou-se que, após quatro dias da aplicação do vapor de etanol, os frutos expostos por 36 horas, a $20^{\circ} \mathrm{C}$, não apresentavam adstringência. Já os frutos expostos por 24 horas, a 20 e $24^{\circ} \mathrm{C}$, levaram seis dias para estarem aptos para o consumo (Figura 2D). Em todos os tratamentos, a firmeza foi mantida acima de $10 \mathrm{~N}$, considerada ainda adequada para a comercialização (Figuras 2A e 2B).

Considerando que a concentração de $3,5 \mathrm{~mL} \mathrm{~kg}^{-1}$ de fruto foi suficiente para promover a destanização, avaliou-se a aplicação da concentração de $1,75 \mathrm{~mL} \mathrm{~kg}{ }^{-1}$ de fruto associada a menores tempos de exposição dos frutos ao etanol. Após 20 dias de armazenamento refrigerado, os frutos apresentavam-se apropriados para o consumo, tanto em relação à adstringência, quanto à firmeza de polpa, independentemente das dosagens e dos tempos de exposição testados (Figuras 3A e 3B).

O processo de destanização pode ser dividido em duas etapas: na primeira, há acúmulo de acetaldeído e, na segunda, a polimerização das moléculas de tanino pelo acetaldeído acumulado na polpa (ITAMURA\& FUKUSHIMA, 1989). Como observado no presente trabalho, é necessário um período de quatro dias à temperatura ambiente para que essas duas etapas sejam concluídas e o processo de destanização seja completo (Figura 2D). Caso o processo de destanização não seja completo, os taninos podem ser ressolubilizados, fato já observado na cultivar 'Triumph' (BEN-ARIE \& SONEGO, 1993). Esse processo é denominado de recuperação da adstringência.

Uma das principais preocupações em relação ao armazenamento refrigerado é a acelerada redução da firmeza de polpa após a remoção dos frutos da refrigeração (ANTONIOLLI et al., 2001; SALVADOR et al., 2007). Na avaliação realizada no dia seguinte à retirada dos frutos do armazenamento a $1^{\circ} \mathrm{C}$, verificou-se significativa redução da firmeza de polpa; porém, os valores se estabilizaram no subsequente período de 14 dias de exposição dos frutos a $20^{\circ} \mathrm{C}$. Comportamento semelhante foi verificado também no tratamento controle, demonstrando pouca influência da aplicação de etanol sobre o amolecimento dos frutos (Figura 3A).

Ciência Rural, v.39, n.7, out, 2009. 


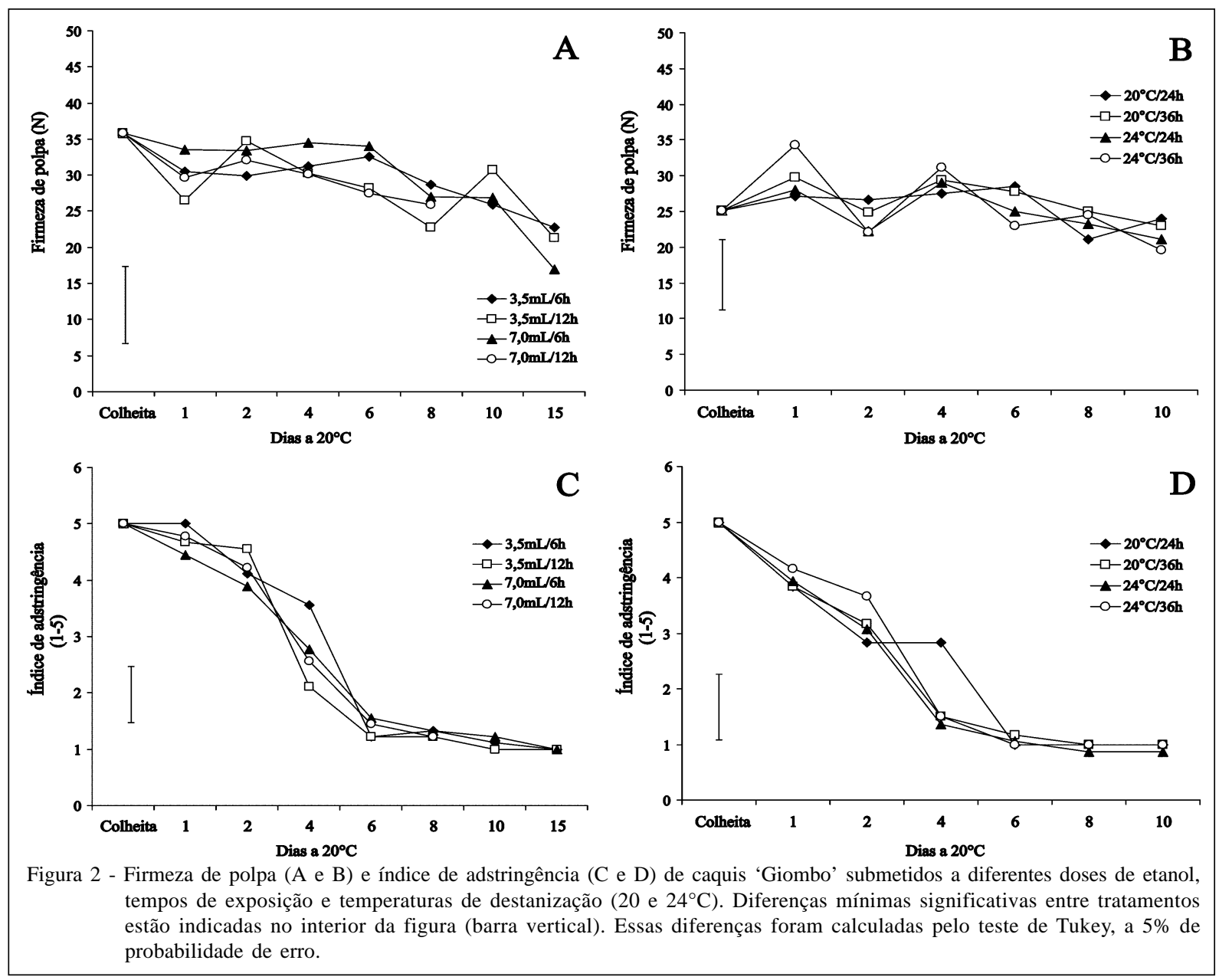

Após a refrigeração, com exceção do tratamento controle que se manteve adstringente durante todo o período analisado, todos os frutos apresentavam-se aptos ao consumo (Figura 3B). De acordo com BEN-ARIE \& SONEGO (1993), após a aplicação do agente destanizador (etanol, etileno ou $\mathrm{CO}_{2}$ ), é necessário um período de 24 horas sob temperatura superior a $20^{\circ} \mathrm{C}$, para promover a polimerização do tanino solúvel. Entretanto, no presente trabalho, os frutos já se encontravam destanizados após a refrigeração sem haver a necessidade da exposição adicional deles a $20^{\circ} \mathrm{C}$. Os valores de índice de cor de casca e de polpa sofreram alterações a cada dia de análise, não apresentando diferença entre os tratamentos (Figuras 3C e 3D).

Os frutos utilizados no experimento 2 apresentavam estádio de maturação mais avançado em relação ao experimento anterior, com coloração de casca mais alaranjada. Após quatro dias da aplicação das doses de etanol, todos os frutos apresentavam-se não adstringentes, inclusive os frutos do tratamento controle (Figura 4E).
Apesar da reduzida perda de massa, os valores observados de firmeza de polpa comprometeram a qualidade dos frutos, inviabilizando a avaliação por período superior a seis dias (Figura 4A e 4C). Tal amolecimento está correlacionado com a degradação da parede celular, mediada principalmente por enzimas pectolíticas. TIAN et al. (1991) observaram diminuição da atividade da pectinametilesterase, aumento da concentração de pectina solúvel e acréscimo da atividade de poligalacturonase, juntamente com o decréscimo na firmeza dos frutos. As pectinas solúveis podem sofrer interações covalentes e não covalentes com as moléculas de taninos solúveis, formando polímeros de taninos, tornando-os insolúveis e, assim, removendo a adstringência dos frutos. Tal ação das pectinas solúveis, liberadas pela degradação das paredes celulares, pode ser a explicação da reduzida adstringência de frutos em estádio avançado de maturação (TAIRA et al., 1997). As proteínas e os açúcares que são hidrolisados durante a senescência também podem reagir e polimerizar as moléculas de 

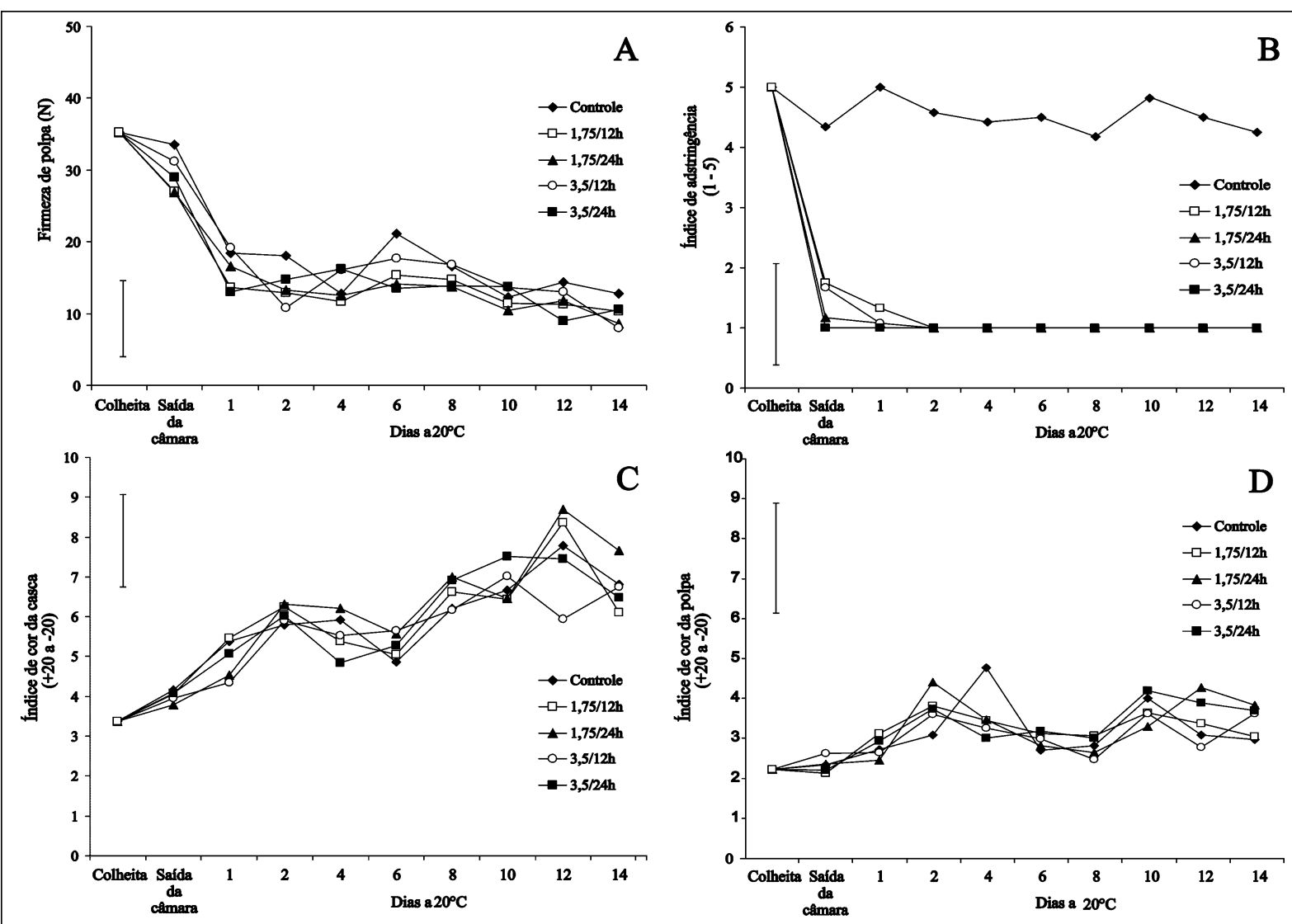

Figura 3 - Parâmetros de qualidade de caquis 'Giombo' submetidos a diferentes doses de etanol e tempos de exposição e armazenados a $1{ }^{\circ} \mathrm{C}$, por 20 dias, com posterior exposição a $20^{\circ} \mathrm{C}$, por 14 dias. Diferenças mínimas significativas entre tratamentos estão indicadas no interior da figura (barra vertical). Essas diferenças foram calculadas pelo teste de Tukey, a 5\% de probabilidade de erro.

tanino (TAIRA et al., 1998). Outra explicação para a destanização de frutos de estádio de maturação avançado, como foi observado no experimento 2, é o acúmulo natural de acetaldeído causado pelo amadurecimento dos frutos, juntamente com o aumento na produção de etileno (PESIS, 2005).

Não foram observadas diferenças significativas entre as concentrações de etanol utilizadas e os tempos de exposição na eficiência de remoção de adstringência. Assim, quanto menor a quantidade de etanol e o tempo de exposição dos frutos, maior será o rendimento, considerando que existirá economia na quantidade de etanol utilizada; a produção e o acúmulo de etileno serão menores; o risco de danos à epiderme causados pelo vapor de etanol será menor e, consequentemente, a vida de prateleira dos frutos será aumentada. Caso os frutos sejam expostos por longos períodos aos vapores de etanol, pode haver a aceleração do amadurecimento, incrementando a perda de firmeza de polpa. Utilizando uma concentração de etanol sete vezes menor e um período de exposição duas vezes inferior ao testado por ANTONIOLLI et al. (2000), obteve-se neste trabalho a mesma eficiência na remoção de adstringência, mantendo-se a firmeza de polpa dos frutos consideravelmente superior aos valores reportados por ANTONIOLLI et al. (2000).

Outro fato importante observado no presente trabalho refere-se à concentração de etanol a ser aplicada visando à remoção da adstringência. A aplicação de etanol pode ser realizada com base na concentração de etanol por quilo de fruto ( $\mathrm{mL}$ de etanol $\mathrm{kg}^{-1}$ de fruto) ou pelo volume da câmara utilizada ( $\mathrm{mL}$ de etanol $\mathrm{L}^{-1}$ por câmara). No experimento preliminar, a aplicação de $7 \mathrm{~mL}$ de etanol $\mathrm{kg}^{-1}$ de fruto resultou em queimadura na casca, devido à supersaturação de etanol na câmara. No primeiro e no segundo experimento, foi utilizada a concentração de $0,6 \mathrm{~mL} \mathrm{~L}^{-1}$ câmara $^{-1}$, sendo essa concentração equivalente a um quarto da concentração de etanol por quilograma de fruto utilizado no experimento preliminar. Como resultado, os frutos foram destanizados normalmente, sem apresentarem danos à casca. Dessa forma, foi possível estabelecer que, para a destanização do caqui ‘Giombo', é necessário aplicar a quantidade de etanol em função da quantidade de frutos e não em relação ao volume de câmara livre.

Ciência Rural, v.39, n.7, out, 2009. 

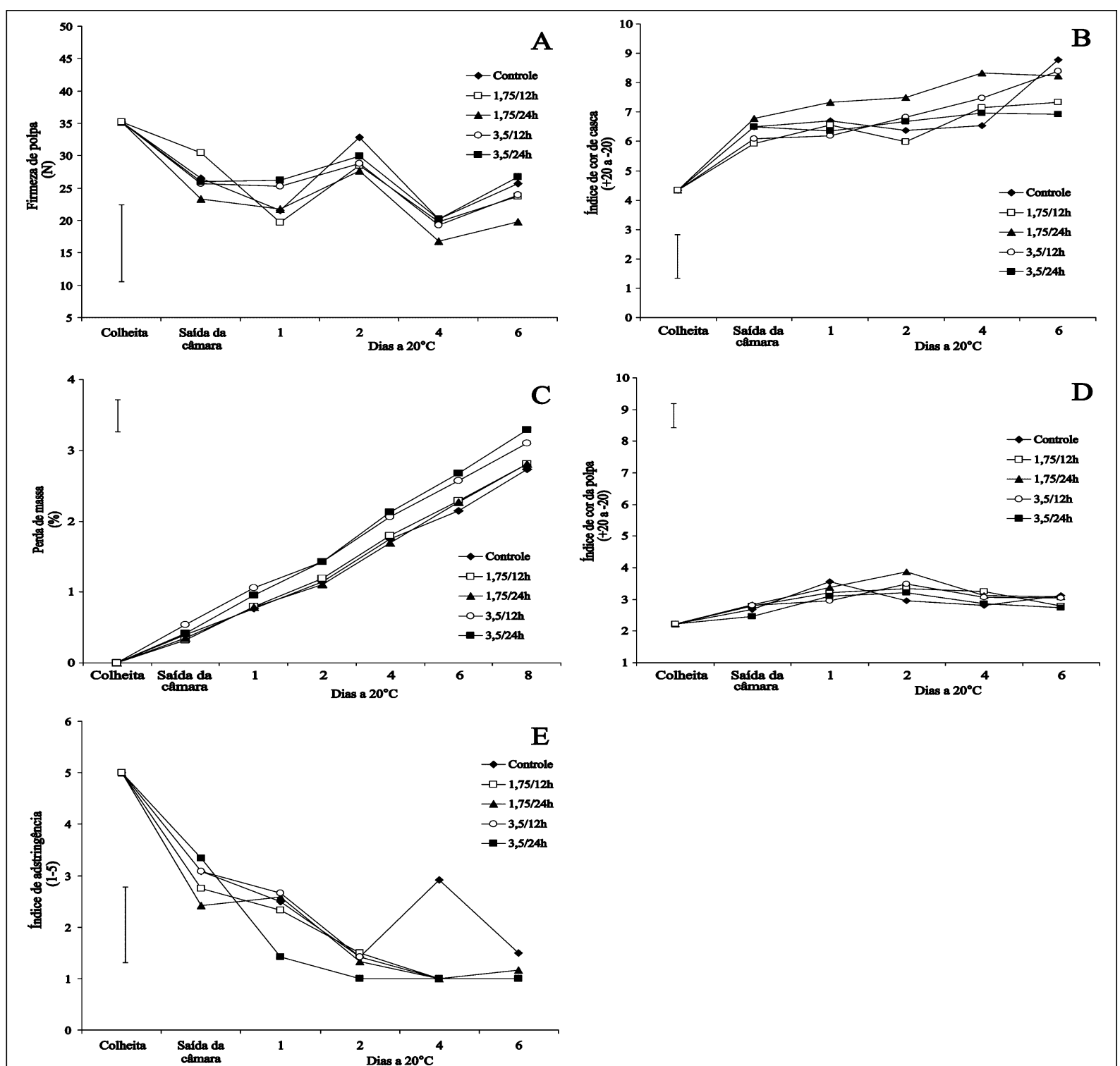

Figura 4 - Parâmetros de qualidade de caquis 'Giombo' submetidos a diferentes doses de etanol e tempos de exposição com posterior exposição dos frutos a $20^{\circ} \mathrm{C}$, por seis dias. Diferenças mínimas significativas entre tratamentos estão indicadas no interior da figura (barra vertical). Essas diferenças foram calculadas pelo teste de Tukey, a 5\% de probabilidade de erro.

O processo de destanização com vapores de etanol demonstrou ser eficiente na remoção da adstringência de caquis ‘Giombo', possivelmente por essa cultivar apresentar uma alta atividade da enzima álcool desidrogenase. Em outras cultivares que não apresentam a mesma eficiência na remoção de adstringência com aplicação de etanol, não foi observada grande atividade dessa enzima responsável pela transformação do etanol em acetaldeído (YAMADA et al., 2002). Dessa forma, mensurando-se a atividade das enzimas formadoras de acetaldeído, seria possível desenvolver um método de remoção de adstringência mais eficiente, o que demandará futuras pesquisas.

\section{CONCLUSÕES}

A aplicação de 3,5mL etanol por quilograma de fruto, por um período de seis horas, é suficiente para a remoção total da adstringência de caquis da cultivar ‘Giombo’ após seis dias da aplicação.

A polimerização das moléculas de tanino, após a aplicação do vapor de álcool etílico, não é influenciada pela refrigeração dos frutos. 


\section{AGRADECIMENTOS}

À Fundação de Amparo à Pesquisa do Estado de São Paulo (FAPESP), pelo auxílio à Pesquisa; à Associação Frutícola do Alto Tietê (AFRUTI), pela doação dos frutos.

\section{REFERÊNCIAS}

ANTONIOLLI, L.R. et al. Influência da embalagem de polietileno na remoção da adstringência e na qualidade de caquis (Diospyros kaki L.) cv. 'Giombo', armazenados sob refrigeração. Revista Brasileira de Fruticultura, v.23, p.293-297, 2001. Disponível em: <http:// dx.doi.org/10.1590/S0100-29452001000200018>. Acesso em: 10 mar. 2009. doi: 10.1590/S0100-29452001000200018.

ANTONIOLLI, L.R. et al. Remoção da adstringência de frutos de caquizeiro 'Giombo' sob diferentes períodos de exposição ao vapor de álcool etílico. Pesquisa Agropecuária Brasileira, v.35, p.2083-2091, 2000. Disponível em: <http://dx.doi.org/ 10.1590/S0100-204X2000001000021>. Acesso em: 10 mar. 2009. doi: 10.1590/S0100-204X2000001000021.

ARNAL, L.; Del RÍO, M.A. Removing astringency by carbon dioxide and nitrogen enriched atmospheres in persimmon fruit cv. Rojo brillante. Journal of Food Science, v.68, p.15161518, 2003. Disponível em: <http://dx.doi.org/10.1111/j.13652621.2003.tb09676.x>. Acesso em: 10 mar. 2009. doi: 10.1111/ j.1365-2621.2003.tb09676.x.

BEN-ARIE, R.; SONEGO, L. Temperature affects astringency removal and recurrence in persimmon. Journal of Food Science, v.58, p.1397-1400, 1993. Disponível em: <http://dx.doi.org/ 10.1111/j.1365-2621.1993.tb06191.x>. Acesso em: 10 mar. 2009. doi: 10.1111/j.1365-2621.1993.tb06191.x.

BEN-ARIE, R. et al. Modified atmosphere packaging for longterm storage of astringent persimmons. Postharvest Biology and Technology, v.1, p.169-179, 1991. Disponível em: <http:/ /dx.doi.org/10.1016/0925-5214(91)90009-Z>. Acesso em: 10 mar. 2009. doi: 10.1016/0925-5214(91)90009-Z.

CAMP-DALL'ORTO, F.A. et al. Novo processo de avaliação da adstringência dos frutos no melhoramento do caquizeiro. Bragantia, v.55, p.237-243, 1996.

ITAMURA, H.; FUKUSHIMA, T. Effects of several treatments on the behavior of tannin in Japanese persimmon fruits. Bulletin Yamagati University, v.10, p.917-922, 1989.

MATSUO, T.; ITOO, S. A model experiment for de-astringency of persimmon fruit with high carbon dioxide treatment: in vitro gelation of kaki-tannin by reacting with acetaldehyde. Agricultural Biological Chemistry, v.46, p.683-689, 1982.
MAZZUZ, C.F. Calidad de frutos cítricos: manual para sugestion desde la recoleccion hasta la expedicion. Barcelona: Ediciones de Horticultura, 1996. 202p.

OSHIDA, M. et al. On the nature of coagulated tannins in astringency-type persimmon fruit after an artificial treatment of astringency removal. Postharvest Biology and Technology, v.8, p.317-327, 1996. Disponível em: <http://dx.doi.org/10.1016/ 0925-5214(96)00016-6>. Acesso em: 10 mar. 2009. doi: 10.1016/0925-5214(96)00016-6.

PESIS, E. The role of the anaerobic metabolites, acetaldehyde and ethanol, in fruit ripening, enhancement of fruit quality and fruit deterioration. Postharvest Biology and Technology, v.37, p.1-19, 2005. Disponível em: <http://dx.doi.org/10.1016/ j.postharvbio.2005.03.001>. Acesso em: 10 mar. 2009. doi: 10.1016/j.postharvbio.2005.03.001.

SALVADOR, A. et al. Influence of ripening stage at harvest on chilling injury symptoms of persimmon cv. Rojo Brillante stored at different temperatures. Food Science and Technology International, v.11, p.359-365, 2005. Disponível em: <http:/ /dx.doi.org/10.1177/1082013205057941>. Acesso em: 10 mar. 2009. doi: $10.1177 / 1082013205057941$.

SALVADOR, A. et al. Physiological and structural changes during ripening and deastringency treatment of persimmon fruit cv. Rojo Brillante. Postharvest Biology and Technology, v.46, p.181-188, 2007. Disponível em: <http://dx.doi.org/ 10.1016/j.postharvbio.2007.05.003>. Acesso em: $10 \mathrm{mar}$. 2009. doi: 10.1016/j.postharvbio.2007.05.003.

TAIRA, S. et al. Reduction of persimmon astringency by complex formation between pectin and tannins. Postharvest Biology and Technology, v.12, p.265-271, 1997. Disponível em: <http://dx.doi.org/10.1016/S0925-5214(97)00064-1>. Acesso em: 10 mar. 2009. doi: 10.1016/S0925-5214(97)00064-1.

TAIRA, S. et al. Effects of freezing rate on astringency reduction in persimmon during and after thawing. Postharvest Biology and Technology, v.14, p.317-324, 1998. Disponível em: $<$ http://dx.doi.org/10.1016/S0925-5214(98)00057-X>. Acesso em: 10 mar. 2009. doi: 10.1016/S0925-5214(98)00057-X.

TIAN, J.W. et al. Study on the physiology of postharvest softening of Diospyros kaki fruits. Plant Physiology Communications, v.2, p.109-111, 1991.

YAMADA, M. et al. Varietal differences in the ease of astringency removal by carbon dioxide gas and ethanol vapor treatments among Oriental astringent persimmons of Japanese and Chinese origin. Scientia Horticulturae, v.94, p.63-72, 2002. Disponível em: <http://dx.doi.org/10.1016/S0304-4238(01)00367-3>. Acesso em: 10 mar. 2009. doi: 10.1016/S0304-4238(01)00367-3. 